\title{
O Imposto Predial e Territorial Urbano (IPTU) e a questão das alíquotas progressivas $^{1}$
}

\author{
Gustavo do Val ${ }^{2}$ \\ Josiane Rosenberger ${ }^{3}$
}

\section{Resumo}

\begin{abstract}
Apresenta considerações gerais acerca da regra-matriz de incidência fiscal do Imposto Predial e Territorial Urbano. Estuda o conceito de progressividade no IPTU e seus fundamentos. Estabelece relação entre as alíquotas progressivas com finalidades fiscais e extrafiscais e os princípios constitucionais. Expõe as posições doutrinárias e jurisprudenciais sobre a possibilidade de coexistência das alíquotas progressivas fiscais e extrafiscais. Conclui pela adoção da progressividade das alíquotas com escopo fiscal e extrafiscal, como instrumento de efetivação da justiça tributária.
\end{abstract}

Palavras-Chave: IPTU; Progressividade fiscal-extrafiscal; Capacidade contributiva; Função social da propriedade; Justiça tributária.

\section{Introdução}

Abordar-se-á ao longo deste trabalho, primordialmente, a progressividade dos impostos, fiscal e extrafiscal, precisamente em relação ao Imposto Predial e Territorial Urbano (IPTU), a qual consiste numa forma do Estado arrecadar tributos com alíquotas variadas para diferentes contribuintes. Para tal estudo explanar-se-á, primeiramente, uma visão abrangente e sucinta sobre a regra-matriz de incidência fiscal do IPTU, visto ser o seu estudo de grande complexidade. Posteriormente, tratar-se-á da progressividade fiscal e extrafiscal, respectivamente, para, então, chegar-se a uma conclusão sobre o tema.

Quanto à progressividade fiscal, será apresentado o seu conceito, bem como concomitantemente os princípios e regras do direito que, de uma mesma forma, delimitam e servem de reforço para a própria caracterização deste mecanismo de tributação, a saber, os princípios da isonomia, da capacidade contributiva e da não-confiscatoriedade.

\footnotetext{
Artigo apresentado como requisito parcial de conclusão da Disciplina de Direito Tributário do Curso de Graduação em Direito da Universidade Estadual de Londrina.

2 Graduando em Direito pela Universidade Estadual de Londrina. gutodoval@yahoo.com.br.

3 Graduanda em Direito pela Universidade Estadual de Londrina. jositj2@yahoo.com.br.
} 
Visualizar-se-á a importância e necessidade de aplicação da progressividade fiscal, uma vez que é através dela que o Estado pratica uma política fiscal mais justa, cobrando dos contribuintes na medida de sua capacidade contributiva, otimizando, assim, o advento de um cenário com menores desigualdades sociais.

Ademais, faz-se necessário apresentar considerações doutrinárias e jurisprudenciais acerca da progressividade extrafiscal em confronto com a de caráter fiscal e da utilização da primeira por parte dos entes tributantes, os Municípios, para fazer valer o princípio que assegura a função social da propriedade, consubstanciada no artigo 5o, XXIII, da Constituição Federal.

\section{Considerações gerais acerca da regra-matriz de incidência fiscal do imposto sobre a propriedade predial e territorial urbana (IPTU)}

A atribuição concedida aos Municípios para instituírem o Imposto sobre a Propriedade Predial e Territorial Urbana encontra fundamento na Constituição Federal, em seu artigo 156, que determina que competem aos municípios instituir impostos sobre propriedade predial e territorial urbana.

Nota-se, diante do preceito supra, a existência de dois critérios materiais, componentes da hipótese tributária: 1) ser proprietário de bem imóvel predial; e 2) ser proprietário de bem imóvel territorial.

Neste ínterim, deve-se salientar que, além do critério material, estabelecido na Lei Maior, referente à propriedade, o Código Tributário Nacional, em seu art. 32, prevê o domínio útil e a posse de bens imóveis por natureza ou por acessão física. Destarte, visualiza-se divergência entre a interpretação restritiva do texto constitucional, o qual alude especificamente ao termo propriedade, e o texto infraconstitucional constante do CTN, anterior à $\mathrm{CF}$, que parece ampliar a atribuição tributária dos Municípios. No entanto, tem-se consolidado na Jurisprudência o entendimento de que o instituto da propriedade, tal como consubstanciado na CF, deve ser interpretado de forma extensiva, de forma a albergar os conceitos de domínio útil e posse ad usucapionem, compatibilizando-se, assim, com o art. 32 do CTN.

Percebe-se que o entendimento acima repercute no critério pessoal em relação ao sujeito passivo, o qual comporá um dos pólos da relação jurídica tributária do IPTU. Vale 150

Revista de Direito PúBlico, Londrina, V. 2, N. 3, P. 149-162, SET./DEZ. 2007. 
mencionar a possibilidade de se aferir a responsabilidade de terceiros, que deverão de alguma forma resguardar vínculo com o critério material da hipótese tributária. Quanto ao sujeito ativo, normalmente, é o Município ou outra pessoa que designado por ele, nos termos da lei municipal.

O critério espacial do imposto em pauta é a zona urbana do Município, conforme explicitado no art. 32, caput, do CTN. A questão aqui reside no fato de se delimitar a área urbana. O CTN dispõe algumas regras para tal procedimento. Porém, considerando este preceito como uma norma federal, e não nacional, por não visar dirimir conflitos de competência, propugna-se pela adoção voluntária dos Municípios, não impositiva. Além do mais, tendo em vista que o planejamento urbano é atribuído constitucionalmente ao Município, tem-se consignado na doutrina e jurisprudência o entendimento de caber ao Município a delimitação de sua zona urbana, seja pelo plano diretor ou por outra lei municipal.

Quanto ao critério temporal do IPTU, em regra, opta-se pelo dia 1 o de janeiro de cada ano. No entanto, nada impede que o Município disponha de forma diversa, de acordo com sua conveniência.

O critério quantitativo da relação jurídica tributária do IPTU se expressa através da base de cálculo, correspondente ao valor venal do imóvel, conforme o art. 33 do CTN. Não é demais mencionar que a base de cálculo, instituída pelos municípios, deve traduzir em um valor mais próximo do real, ou seja, igual ao valor de mercado do imóvel, conjugando-se com a alíquota, fração fixa ou variável do valor venal do imóvel.

$\mathrm{O}$ art. 156, em seu $\S 1$, , da CF autoriza a fixação de alíquotas progressivas - tema central do presente trabalho - de acordo com o valor do imóvel (progressividade fiscal, que visa à concretização do princípio da capacidade contributiva, com fins meramente arrecadatórios) e a fixação de alíquotas distintas de acordo com a localização e o uso do imóvel (progressividade extrafiscal, que atende ao princípio da função social da propriedade). Esta última, para alguns, só é válida se condizente com as diretrizes fixadas no Plano Diretor do Município.

O inciso II do §4으 do art. 182 da CF autoriza o Município a, mediante lei específica, instituir IPTU com alíquota progressiva em caráter sancionatório àqueles proprietários que não estiverem cumprindo a determinação municipal de adequado aproveitamento do solo 
urbano não edificado, subutilizado ou não utilizado, em área incluída no Plano Diretor. A Lei 10.257/2001 (Estatuto da Cidade) regulou esta matéria em seu art. 7ํ. Entretanto, por se tratar de lei federal, entende-se que os Municípios podem admiti-la ou não, tendo em vista ser esta uma matéria reservada à lei complementar, nos termos do art. 146, III, da CF.

O lançamento do IPTU é feito de ofício pela Administração Pública, anualmente. O Município declara o fato jurídico tributário, identifica o sujeito passivo, avalia o imóvel e aplica-Ihe a alíquota para fins de determinação do montante a ser pago. O lançamento baseia-se em cadastros imobiliários constantes dos Cartórios de Registros de Imóveis.

Em seguida, notificam-se os contribuintes para pagamento dentro de certo prazo. Em não sendo fixado prazo, aplica-se o art. 160 do CTN, que estabelece o prazo de 30 dias para pagamento, contados a partir da notificação.

O prazo decadencial para a produção da norma concreta e individual é de cinco anos, contados a partir do 10 dia do exercício financeiro seguinte àquele em que 0 lançamento poderia ter sido efetuado (CTN, art. 173, I).

Compete ao contribuinte, como dever instrumental, ainda que isento, inscrever-se no Cadastro Fiscal de Propriedades Imobiliárias do Município. Ademais, deve-se apresentar, para fins de inscrição, uma declaração contendo elementos informativos do imóvel. Destacase que este dever é dispensável quando as declarações posteriores trouxerem somente informações repetidas. No caso de alterações no imóvel, que resultem na modificação da base de cálculo, deverão as mesmas ser comunicadas ao ente tributante, para fins de atualização do Cadastro Imobiliário junto à Prefeitura.

É possível que a legislação municipal determine outros deveres instrumentais aos contribuintes de acordo com a necessidade, devendo-se sempre levar em conta o princípio da celeridade na Administração Pública.

\section{Progressividade fiscal e o princípio da capacidade contributiva no IPTU}

A progressividade fiscal está prevista no inciso I do §1으 do art. 156 da CF ao explicitar que o IPTU poderá ser progressivo em razão do valor do imóvel. Consiste, em linguagem simples, em uma forma de o Estado tratar diferentemente os contribuintes quanto ao valor que os mesmos devem contribuir para a manutenção da coisa pública, levando em consideração a sua capacidade contributiva. Com esta postura, o Estado busca 
fins meramente fiscais, sendo que o objetivo é tão-somente abastecer os cofres públicos. Por este motivo, deve-se atentar para o valor que cada contribuinte pode pagar, cobrando mais de quem tem mais.

A progressividade fiscal referente ao IPTU tem sua aplicação através da variação das alíquotas em relação aos diferentes contribuintes, pois a base de cálculo, como se sabe, será sempre a mesma, o valor venal do imóvel.

No entanto, é preciso diferenciar proporcionalidade de progressividade fiscal. Alíquotas proporcionais não resultam em uma cobrança proporcionalmente dita, na óptica da capacidade contributiva, uma vez que a mesma se manifesta unicamente em relação à base de cálculo. Somente a progressividade de alíquotas resultará numa "proporcionalidade" real entre os contribuintes de diferentes capacidades contributivas. Em conformidade com o exposto, cita-se o pensamento de Valéria Furlan (2004, p. 112):

\footnotetext{
A nosso sentir, os impostos - quanto ao critério da variação da alíquota ou da base de cálculo - podem ser classificados apenas em (1) aparentemente proporcionais e (2) progressivos (ou efetivamente proporcionais) e regressivos (ou efetivamente não proporcionais) - neste último caso, conforme o parâmetro que se tenha por referência.
}

Contudo, à progressividade fiscal apresentam-se determinados limites, os quais norteiam sua correta aplicação, ao mesmo tempo em que explicitam melhor o seu entendimento, como o princípio da isonomia e as disposições constitucionais de respeito à capacidade contributiva e a não-confiscatoriedade, explanadas a seguir.

O princípio da isonomia está positivado no caput do art. 5ㅇ da CF. De acordo com esse princípio, o legislador deve buscar corrigir as desigualdades naturais, por meio de um tratamento desigual aos desiguais, na medida de suas desigualdades. Em direito tributário, somente se alcança tal tratamento por meio da progressão das alíquotas, as quais conduzem a uma justa arrecadação fiscal.

A aplicação de alíquotas fixas meramente proporcionais no IPTU fere o princípio da isonomia, uma vez que faz incidir o imposto em proporções iguais para contribuintes diferentes detentores de capacidade contributiva. Exemplificando: uma alíquota de 1\% para um imóvel de valor $X$ pode resultar em uma quantia considerável do orçamento do respectivo contribuinte; mas, a mesma alíquota aplicada a um imóvel de valor 100X resultará 
num quantum devido não tão significativo ao respectivo contribuinte, levando-se em consideração sua capacidade contributiva. Coaduna, neste entendimento, a autora Valéria Furlan (2004, p. 114):

Mas por que se estaria ferindo o princípio da isonomia? Por que a alíquota única acarreta uma suposta proporcionalidade, isto é, não trata desigualmente os desiguais, na medida de suas desigualdades. Apenas as alíquotas progressivas permitem que quem tem mais pague mais do que quem tem menos, [...]

A capacidade contributiva é um desdobramento do princípio da isonomia, consignada no $\S 1$ 을 do art. 145 da CF, através da qual devem ser respeitadas as diferentes capacidades contributivas dos contribuintes, o que, transferindo-se para a aplicação do IPTU, resulta no dever de se adotar alíquotas diferentes conforme as diferentes bases de cálculo. Isto por que é a base de cálculo - valor venal do imóvel - que expressa a capacidade contributiva do contribuinte, no caso do IPTU.

Retomando o exemplo anterior, pode-se utilizá-lo para explicitar melhor o tema. Nota-se que o proprietário detentor do imóvel com valor $\mathrm{X}$ tem que pagar aos cofres públicos uma quantia considerável, o que o faz dispor de determinado valor relevante em seu orçamento familiar. Na hipótese do detentor do imóvel de valor 100X, aplicando-se a mesma alíquota o valor apurado será proporcional, levando-se em conta a base de cálculo. Porém, o respectivo valor apurado não consubstanciará um valor de igual importância num orçamento familiar, em comparação ao outro contribuinte, pois a capacidade econômica do segundo é maior, ou seja, para que o segundo contribuinte, o detentor do imóvel de valor 100X, tivesse uma parcela de seu orçamento comprometida proporcionalmente a do primeiro, a alíquota de seu IPTU precisaria ser maior. Compartilhando desse entendimento, o Professor Roque Carrazza (2005, p. 85) assevera:

O princípio da capacidade contributiva hospeda-se nas dobras do princípio da igualdade e ajuda a realizar, no campo tributário, os ideais republicanos. Realmente, é justo e jurídico que quem, em termos econômicos, tem muito pague, proporcionalmente, mais imposto do que quem tem pouco. Quem tem maior riqueza deve, em termos proporcionais, pagar mais imposto do que quem tem menos riqueza. Noutras palavras, deve contribuir mais para a manutenção da coisa pública. As pessoas, pois, devem pagar impostos na proporção dos seus haveres, ou seja, de seus índices de riquezas. 
E o ilustre autor complementa:

Em relação ao imposto sobre propriedade (imposto territorial rural, imposto predial e territorial urbano, imposto sobre a propriedade de veículos automotores, etc.), a capacidade contributiva revela-se com o próprio bem, porque a riqueza não advém apenas da moeda corrente, mas também do patrimônio, como um todo considerado (CARRAZA, 2005, p. 89).

Quanto à não-confiscatoriedade, tem-se que as alíquotas a serem fixadas para a apuração do valor devido, a título de IPTU, não podem ser tão altas a ponto de traduzirem um efeito de confisco da renda ou do patrimônio do contribuinte.

Mais uma vez, recorre-se às lições do ilustre Professor Roque Carrazza, a fim de analisar o tema da não-confiscatoriedade:

Estamos convencidos de que o princípio da não-confiscatoriedade, contido no art. 150 , IV, da CF (pelo qual é vedado 'utilizar tributo com efeito de confisco'), deriva do princípio da capacidade contributiva. Realmente, as leis que criam impostos, ao levarem em conta a capacidade econômica dos contribuintes, não podem compelilos a colaborar com os cofres públicos além de suas possibilidades. Estamos vendo que é confiscatório o imposto que, por assim dizer, 'esgota' a riqueza tributável das pessoas, isto é, não leva em conta suas capacidades contributivas (grifo do autor) (CARRAZA, 2005, p. 98).

Aplicando-se a referida argumentação ao presente trabalho, entende-se que será confiscatório o IPTU que detiver uma alíquota excessiva, a ponto de resultar num quantum devido, próximo, aproxima, ainda que de longe, ao valor do imóvel, pois a capacidade contributiva no IPTU é medida pelo valor venal do imóvel. Explicitando melhor, não poderá o valor devido do imposto ser correspondente a uma parcela considerável do próprio imóvel, uma vez que estaria incidindo sobre parte do capital do contribuinte, levando-se em consideração que sua reiterada cobrança implicará, em pouco tempo, a apreensão de um valor correspondente ao próprio imóvel, caracterizando, assim, um efeito de confisco.

Nessa linha de raciocínio, apresentam-se as lições de Castilho (2002, p. 39):

É adequado afirmar que confisco tributário consiste em uma ação do Estado, empreendida pela utilização de tributo, a qual retira a totalidade ou uma parcela considerável da propriedade do cidadão contribuinte, sem qualquer retribuição econômica ou financeira por tal ato. 
Do exposto, conclui-se que os Municípios devem aplicar as alíquotas progressivas em relação às diferentes bases de cálculo, ao tributarem os proprietários de bem imóvel predial e territorial, para que, através de uma justa progressividade fiscal, consubstancie-se um dos mais importantes princípios da Constituição Federal, qual seja, o da isonomia.

\title{
4 Problematização acerca da progressividade extrafiscal no IPTU
}

A finalidade precípua do Estado ao impor a tributação aos membros de sua coletividade é o abastecimento dos cofres públicos, visando, assim, o equilíbrio financeiro do mesmo, em virtude das significativas despesas geradas pela máquina estatal.

Contudo, a tributação por parte do Estado atual não objetiva tão-somente a finalidade ordinária ou meramente fiscal. Conforme exposto por Fabio Brun Goldschmidt (2004, p. 187)

\begin{abstract}
O Estado moderno vem mais e mais assumindo um papel intervencionista e, independentemente do tipo de ideologia que se adote, esse parece ser um caminho sem retorno. A proteção da saúde, do meio ambiente e da concorrência, a globalização ou o simples anseio pela redistribuição de rendas são fatores que têm estimulado a ação positiva do Estado no controle dos administrados. Isso coloca em questão a própria necessidade de revisão de uma série de fundamentos do direito tributário e financeiro que, segundo pensamos, nem sempre se adequam aos anseios de utilização da tributação com finalidades que transbordem aquelas meramente arrecadatórias.
\end{abstract}

Destarte, infere-se que, à tributação com finalidade ordinária, pode-se atrelar a intenção do Estado-legislador, através da imposição tributária, de alcançar fins outros diversos dos fiscais. Nesse ínterim, citam-se os objetivos sociais, políticos e/ou econômicos, os quais são atingidos indiretamente pelo mecanismo da tributação com alíquotas diferenciadas, independentemente da alteração da base de cálculo. Tem-se o que se denomina, por expressiva parcela dos juristas, de progressividade extrafiscal.

O Imposto sobre Propriedade Predial e Territorial Urbana (IPTU) consiste em uma das formas mais relevante para o Município arrecadar suas receitas. Comumente, observa-se que o ente tributante estabelece alíquotas progressivas em razão do valor do imóvel, baseando-se no princípio da capacidade contributiva. Porém, o Município, no uso de sua atribuição constitucional, pode e deve, nas lições de Souto Maior Borges, em cumprimento 
ao disposto no artigo 156, § 1으, II da Constituição Federal, fixar alíquotas diferenciadas conforme a localização e o uso do imóvel (BORGES apud CARRAZA, 2005, p. 107).

Desta feita, as diferentes alíquotas aplicadas a situações diversas estimulam ou desestimulam os contribuintes a adotar uma ou outra conduta com a relação à propriedade. Daí, a razão de adotar-se a progressividade extrafiscal, nos ensinamentos de Alfredo Augusto Becker (apud FURLAN, 2004, p. 149), como meio indireto de disciplinar o comportamento social, característica esta que a difere da sanção, uma forma direta utilizada pelo Estado com o intuito de impor ou proibir certas condutas.

O escopo da progressividade extrafiscal para o imposto em pauta fundamenta-se no princípio estatuído nos artigos 5ำ, XXIII e 182, § 2으 da Constituição Federal, qual seja, a função social da propriedade. O ilustre jurista José Afonso da Silva (apud FURLAN, 2004, p. 146-147) aduz que o direito de propriedade não tem caráter absoluto, nem tampouco se traduz em um direito individual puro, razão pela qual, o proprietário e, ainda, no caso do IPTU, o possuidor ad usucapionem, bem como o titular do domínio útil devem cumprir a função social da propriedade em benefício da coletividade.

Em que pese a finalidade extrafiscal do IPTU visar o atendimento à função social da propriedade, bem como a progressividade das alíquotas para alcançar citado fim ser alterada independentemente da base de cálculo, não se pode olvidar, porém, que a aludida tributação deve respeitar o princípio do não-confisco. Nesse sentido, Fabio Goldschmidt (2004, p. 195) expõe sua idéia:

\begin{abstract}
Admite-se uma elevação da tributação por conta da extrafiscalidade (quando a mesma esteja permitida, evidentemente), mas essa elevação não pode chegar à medida da destruição, da penalização, ou da aniquilação de outros direitos do contribuinte, mesmo porque o contribuinte não excepcionou a observância do art. 150, IV, nas hipóteses em que permitiu o uso extrafiscal da tributação. Ou seja, o princípio do não-confisco não só é plenamente aplicável à extrafiscalidade, como igualmente não sofre qualquer restrição no que concerne aos seus contornos qualitativos (salvo casos expressos).
\end{abstract}

Dessa forma, tem-se que a progressividade extrafiscal do IPTU não poderá acarretar encargos ao contribuinte, de modo que se mostre incoerente com os fins propostos, cabendo ao Poder Judiciário analisar cada caso concreto para aferir eventual confisco.

Ademais, a tributação com finalidade extrafiscal, assim como a de caráter fiscal, deverá submeter-se ao regime jurídico-constitucional próprio dos impostos e aos princípios 
que Ihe são inerentes. Consoante o exposto, mostram-se os ensinamentos de Paulo de Barros Carvalho (2005, p. 236):

Consistindo a extrafiscalidade no emprego de fórmulas jurídico-tributárias para a obtenção de metas que prevalecem sobre os fins simplesmente arrecadatórios de recursos monetários, o regime que há de dirigir tal atividade não poderia deixar de ser aquele próprio das exações tributárias. Significa, portanto, que, ao construir suas pretensões extrafiscais, deverá o legislador pautar-se, inteiramente, dentro dos parâmetros constitucionais, observando as limitações de sua competência impositiva e os princípios superiores que regem a matéria, assim os expressos que os implícitos (grifo do autor).

Em face das lições supra, depreende-se que a despeito de o IPTU ter ou não finalidades extrafiscais, pois fiscais sempre haverá, este tipo de tributação não precisa atender a algum regime especial, senão aquele que é próprio para esse tipo de exação tributária estabelecida no texto constitucional.

Contudo, existe divergência doutrinária e jurisprudencial acerca dos dispositivos constitucionais referentes à progressividade do IPTU. Tratam-se dos arts. 145, § 1ㅇ, 156, § 1으, e 182, § 4으, II, da Constituição Federal de 1988, transcritos a seguir:

Art. 145. (...)

$1-(\ldots)$

II $-(\ldots)$

III $-(\ldots)$

$\S 1$ 10 Sempre que possível, os impostos terão caráter pessoal e serão graduados segundo a capacidade econômica do contribuinte, facultado à administração tributária, especialmente para conferir efetividade a esses objetivos, identificar, respeitados os direitos individuais e nos termos da lei, o patrimônio, os rendimentos e as atividades econômicas do contribuinte.

Art. 156. Compete aos Municípios instituir impostos sobre:

I - propriedade predial e territorial urbana;

II $-(\ldots)$

III- $-(\ldots)$

IV $-(\ldots)$

$\S 1$ o Sem prejuízo da progressividade no tempo a que se refere o art. 182, § 4으, inciso II, o imposto previsto no inciso I poderá:

I - ser progressivo em razão do valor do imóvel; e

II - ter alíquotas diferentes de acordo com a localização e o uso do imóvel.

Art. 182. A política de desenvolvimento urbano, executada pelo Poder Público municipal, conforme diretrizes gerais fixadas em lei, tem por objetivo ordenar o pleno desenvolvimento das funções sociais da cidade e garantir o bem-estar de seus habitantes.

$\S 10(\ldots)$

$\S 2 \circ(\ldots)$ 


\begin{abstract}
$\S 30(\ldots)$
$\S 4$ ㅇ É facultado ao Poder Público municipal, mediante lei específica para área incluída no plano diretor, exigir, nos termos da lei federal, do proprietário do solo urbano não edificado, subutilizado ou não utilizado, que promova seu adequado aproveitamento, sob pena, sucessivamente de:

$1-(\ldots)$

II - imposto sobre a propriedade predial e territorial urbana progressivo no tempo;
\end{abstract}

Com referência aos preceitos normativos supracitados, discute-se sobre a autonomia da progressividade prevista no art. 156, § 10, em relação à mencionada no art. $182, \S 40$, II, da Lei Maior. De um lado, há os que pugnam pela progressividade fiscal, pois o princípio da capacidade contributiva deve ser respeitado, na medida do possível, quando da instituição dos impostos. Por outro lado, os que admitem unicamente a progressividade extrafiscal, em atendimento ao princípio da função social da propriedade.

A primeira corrente doutrinária, seguida por Geraldo Ataliba e Roque Carraza, entre outros, defende a possibilidade de coexistência entre a tributação com progressividades fiscal e extrafiscal. Segundo Hugo de Brito Machado (apud FURLAN, 2004, p. 167), admitindo-se, tão-somente, a tributação com caráter extrafiscal, descartar-se-ía, por completo, o art. 156, $\S 10$, da CF, restando-se absolutamente inutilizável, devendo-se, porém, conjugar os princípios da função social da propriedade e da capacidade contributiva. Nesse mesmo sentido, as palavras do jurista Roque Carraza (2005, p. 109):

\begin{abstract}
A Constituição quer que, além de obedecer ao princípio da capacidade contributiva, o IPTU tenha alíquotas diferentes de acordo com a localização e o uso do imóvel, de forma a assegurar o cumprimento da função social da propriedade (nos termos do plano diretor). Em outras palavras, além de obedecer a uma progressividade

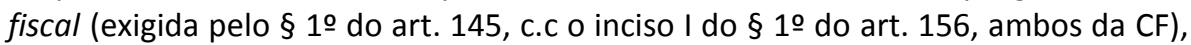
o IPTU deverá submeter-se a uma progressividade extrafiscal (determinada no inciso II do $\S 1$ o do art. 156 da CF) (grifo do autor).
\end{abstract}

Percebe-se, pois que, para essa corrente doutrinária, o princípio da capacidade contributiva, característico dos impostos, não impede a tributação do IPTU utilizando-se a progressividade extrafiscal.

Diferentemente, a segunda corrente doutrinária, tendo como adeptos, por exemplo, Marco Aurélio Greco e Aires Fernandino Barreto, dentre outros. Para este autor, a essência da progressividade do IPTU não está no princípio da capacidade contributiva, mas apenas naquele que assegura a função social da propriedade, sendo inconstitucional, por 
conseguinte, a progressividade adotada em relação ao valor do imóvel. Acompanhando o autor, Mauro Aurélio Greco (apud FURLAN, 2004, p. 171) assevera:

[...] não há na Constituição dois tipos de progressividade do IPTU. Há apenas a que sirva para assegurar a função social do imóvel, nas hipóteses, através do regime e pelos instrumentos consagrados no art. $182 \mathrm{da}$ CF.

Assentado, pois, o entendimento da segunda corrente, em admitir, em consagração ao princípio da função social da propriedade, a progressividade com caráter extrafiscal.

Importante ressaltar, também, que o Supremo Tribunal Federal tem consolidado seu posicionamento em relação ao tema no sentido de adotar somente a progressividade extrafiscal. É o que se infere da ementa abaixo:

\section{IPTU. Progressividade.}

No sistema tributário nacional é o IPTU inequivocamente um imposto real.

Sob o império da atual Constituição, não é admitida a progressividade fiscal do IPTU, quer com base exclusivamente no seu artigo 145, § 10, porque esse imposto tem caráter real que é incompatível com a progressividade decorrente da capacidade econômica do contribuinte, quer com arrimo na conjugação desse dispositivo constitucional (genérico) com o artigo 156, § 1 - (específico).

A interpretação sistemática da Constituição conduz inequivocamente à conclusão de que o IPTU com finalidade extrafiscal a que alude o inciso II do $\S 4$ o do artigo 182 é a explicitação especificada, inclusive com limitação temporal, do IPTU com finalidade extrafiscal aludido no artigo 156, I, § 1ㅇ.

Portanto, é inconstitucional qualquer progressividade, em se tratando do IPTU, que não atenda exclusivamente ao disposto no artigo 156, §10, aplicado com as limitações expressamente constantes dos $\S \S 2$ e e 40 do artigo 182, ambos da Constituição Federal.

Recurso extraordinário conhecido e provido, declarando-se inconstitucional o subitem 2.2.3 do setor II da Tabela III da Lei 5.641, de 22.12.89, no município de Belo Horizonte (RE 153.771, Pleno, Min. Rel. Moreira Alves, DJ 05.09.97)

Em que pese tal ementa referir-se a julgado de 1997, anterior à EC n. 29/2000, que deu nova redação ao § 1 o do art. 156 da CF, acrescentando os incisos I e II, o entendimento jurisprudencial da Suprema Corte tem se mostrado o mesmo, concluindo pela inconstitucionalidade da progressividade fiscal, baseando-se, principalmente, no argumento de que, por se tratar de imposto de natureza real, não há como deduzir a capacidade econômica do contribuinte e aplicar alíquotas diferentes em razão do valor do imóvel. 


\section{Conclusão}

Das considerações retro, conclui-se que é dever do Município aplicar alíquotas efetivamente proporcionais à capacidade contributiva dos contribuintes - as alíquotas progressivas, ao instituírem o IPTU, em respeito aos princípios constitucionais.

Destarte, com o devido acato aos limites impostos pelos princípios da capacidade contributiva e da não-confiscatoriedade, o Município deve arrecadar mais de quem tem mais a pagar, com o intuito de concretizar os objetivos do princípio da isonomia e, sobretudo, da Constituição Federal.

Contudo, a progressividade do IPTU não deve se restringir tão-somente ao escopo fiscal, mas atrelar-se a finalidades outras, precipuamente, atender ao princípio consignado no texto constitucional, em seu art. 5, XXIII, qual seja, a função social da propriedade.

Aduz-se que a propriedade não tem caráter absoluto, nem se constitui em um direito individual puro, devendo o proprietário do bem imóvel, aquele que detém o seu domínio útil e o possuidor ad usucapionem darem função social à propriedade, em favor da coletividade. Com esse objetivo, nada mais eficaz que um mecanismo de tributação que, além de medir a capacidade econômica do contribuinte, o estimulará a adotar as posturas corretas frente ao princípio constitucional supra.

A despeito das respeitáveis posições doutrinárias e jurisprudenciais da Suprema Corte, pugna-se pela progressividade fiscal e extrafiscal, concomitantemente, como instrumento de efetivação dos princípios constitucionais da capacidade econômica do contribuinte e da função social da propriedade, respectivamente, a fim de haja justiça tributária, preconizada no texto constitucional como valor supremo e objetivo fundamental da República Federativa do Brasil.

\section{Referências}

CARRAZA, Roque Antonio. Curso de Direito Constitucional Tributário. 21. ed. rev. ampl. atualizada até a Emenda Constitucional n. 48/2005. São Paulo: Malheiros, 2005.

CARVALHO, Paulo de Barros. Curso de Direito Tributário. 17. ed. São Paulo: Saraiva, 2005.

CASTILHO, Paulo Cesar Baria. Confisco Tributário. São Paulo: Editora Revista dos Tribunais, 2002. 
FURLAN, Valéria. Imposto Predial e Territorial Urbano. 2. ed. rev. atual. ampl. São Paulo: Malheiros, 2004.

GOLDSCHMIDT, Fabio Brun. O Princípio do Não-confisco no Direito Tributário. São Paulo: Revista dos Tribunais, 2004. 